\title{
Applications of Building Information Modeling in Electrical Systems Design
}

\author{
Jasim Farooq ${ }^{1}$, Paawan Sharma ${ }^{1}$ and Sreerama Kumar $\mathbf{R}^{2}$ \\ ${ }^{1}$ School of Engineering, University of Petroleum \& Energy Studies, Dehradun- 248007, India. \\ ${ }^{2}$ Department of Electrical and Computer Engineering, King Abdulaziz University Jeddah, Saudi Arabia.
}

Received 16 October 2017; Accepted 7 December 2017

\begin{abstract}
Building Information Modelling (BIM) is an object-oriented approach that can virtually create a 3D digital model of a building capable of doing realistic engineering analysis well before the construction begins. BIM offers sophisticated tools for electrical trade design and estimation. This paper primarily investigates with supportive case studies, the potential applications of BIM in electrical system design and analysis. Further, its energy analysis, geographical scale significance and smart built environmental applications are also investigated. This research emphasizes on the deployment of BIM at both static and dynamic level for electrical trade such that BIM electrical system design can be made more attractive and more cost effective. The preliminary investigations indicate that seamless integration of semantic information system of BIM with Geographical Information System (GIS) can be very useful for electrical grid optimization and city energy modelling.
\end{abstract}

Keywords: BIM, Electrical design, Energy analysis, GIS, Power system planning, Application Programming Interface (API), Parametric modelling.

\section{Introduction}

Building Information Modelling (BIM) is a digital depiction of our construction requirements which provides more effective methods of planning, designing, maintaining and managing them. It is a collective information reserve of an asset forming a consistent base for various decisions of its lifecycle from its initial feasibility study to demolition [1]. Even though the notion of BIM had its origin since 1970s [2] and then known under different terminologies, it is being popularized since a decade only. By its debut in 1987, ArchiCAD of Graphisoft which supports 2D and 3D is considered to be the first implementation of BIM [3]. Various researchers have shown the effectiveness of BIM for reducing various construction losses, cost, time delays and thereby increasing the productivity [4]. BIM model having a coherent spatial and temporal relationship between building artefacts, combined analysis of different streams is feasible. Reducing rework, raising productivity, decreasing labor costs, and better consistency of the work product are the attractive features of BIM. BIM has evolved and has been recognized by many governments [5], [6] and industries [7]. Many countries are mandating BIM modelling for their construction projects as per the respective BIM requirements [5]. Accepting the potential of BIM well known vendors are providing leading edge and fully complied BIM family files for their products and the files are becoming more and more data rich [7]. According to Smart Market BIM Research report by McGraw Hill Construction $75 \%$ of contractors says that Return on

\footnotetext{
*E-mail address: jasimfaroog@gmail.com

ISSN: $1791-2377$ @ 2017 Eastern Macedonia and Thrace Institute of Technology. All rights reserved. doi:10.25103/jestr.106.16
}

Investment (ROI) is positive by adapting BIM, especially in Japan, Germany and France. Electrical contractors of France are utilizing BIM for $77 \%$ of their projects. The most important activities which the contractors attempt in order to leverage BIM are multi-trade co-ordination, visualization of the design intent and modeling for constructability evaluation [8].

Worldwide, BIM expertise is becoming a prequalification for architecture, engineering and construction (AEC) contractors for bidding a construction project. BIM is basically a computer-aided modeling and possibly all artefacts are embedded with substantial information directly from the manufacturer itself. BIM can be carried out for residential, commercial and industrial projects for both indoor and outdoor type, like indoor or outdoor substations. Studies are also conducted for the usage of BIM in ship, data center and hydel dam construction [9], [10]. The detailing of BIM modelling depends on Level of Detail (LoD) which denotes the volume of information ingrained in BIM Modelling and precise understanding of LoD requirements is the key for the extend of modelling. The major application of BIM in electrical design are semantic information system supported 3D modelling of systems such as lighting, power, cable routing and low current systems. The major BIM based analyses of electrical systems include renewable energy potential assessment, integrated energy analysis, and daylight analysis, circuit checking and Mechanical, Electrical and Plumbing (MEP) coordination. Autodesk's Revit [11] and Graphisoft's ArchiCAD [12] are both BIM based applications. Both are matured packages having their own merits. Bentley Systems' Bentley Substation [13] and Entegra's Primtech [14] are BIM based substation design applications.. Bidirectional ordered integration of BIM with GIS is done 
by bringing the heterogeneous data to a common platform for manipulation.

Traditionally a combination of electrical applications are used for electrical system design (ESD) and the results are depicted in 2D CAD drawings. For example, in lighting system design for a room, luminaires for each area is selected according to Lux requirements and calculated using applications like DIALux [15]. To conduct a study involving design and analysis in DIALux application it is required to collect room dimensions, door and window details, furniture details and material data from architectural drawings. While we do a design from multiple platforms, probability of error are many and also there is the issue of double work. Obviously, it is a tedious process for an electrical engineer because of the need to collect the required details from civil and architectural drawings. The same issue of double work happens when data is collected from a printed catalogue and do drafting in 2D CAD. While drafting the drawings in 2D $\mathrm{CAD}$ there is no functional relationship between the components of drawing. So arithmetic interlinking is not possible. For example a 2D CAD drafted panel board data is not functionally interlinked with corresponding loads. If there is change of data in one entity the applicable change in data of other entity is to be done manually. Also, the change in lighting or power panel data leads to corresponding manual updating of Distribution Frames and Main Distribution Frames. Again updating of feeder schedule is necessary accordingly. In general revisions or alternatives are present in any ESD. So the manual updating becomes a cumbersome task for designers. Visualization of 2D CAD drawings may be vague in nature for developers. Also for preparing section drawings many files are to be referred for drafting. Lack of a consolidated model leads to poor documentation. For conducting an electrical load detailed study in a 2D CAD, manual counting is to be done that leads to more time consumption and cost. Composite design drawings for MEP coordination for detecting the clashes or clearance rules between two systems etc. are error prone with 2D drawings. Thus chances of errors in analysis and documentation will be more in ESD by manual compilation of various parameters from $2 \mathrm{D}$ CAD drawings.

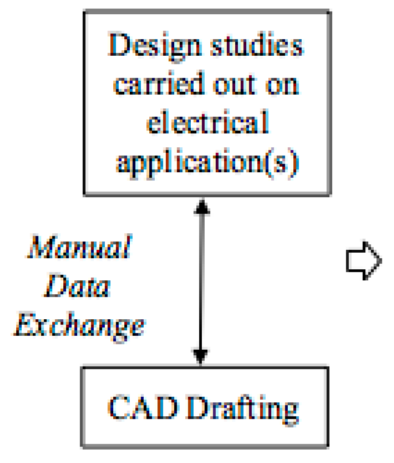

(a)

\begin{tabular}{|c|}
\hline BIM (Integrated \\
repository of \\
information) capable to \\
do Drafting, \\
calculations, analysis \\
and estimation, \\
planning in one \\
platform \\
\hline
\end{tabular}

(b)
Fig.1. Difference between Traditional and BIM based Electrical system design

Generally, MEP designs are unique to each individual project. Furthermore complexity in electrical infrastructure design is continuously increasing due to the increased number of systems such as European Installation Bus (EIB) lighting, smart technologies and Building Management System (BMS). ESD by considering energy saving and sustainable concepts demands a fast and accurate calculation approach. At the same time, requirements of handling huge data and thereby getting accurate results along with the coordination among them becomes a tedious and time consuming process. Thus BIM evolves as a necessity to overcome these issues of current practices in the design and analysis of electrical systems. As shown in Fig. 1a, the traditional method offer manual or semiautomatic manyplatforms method for ESD, whereas BIM offers an integrated repository of information in a single platform as shown in Fig. 1b.

This paper investigates the BIM based ESD potentials, its application in GIS level power system planning and smart built environments (SBE). BIM potentials related to electrical design are described in Tab.1 and the following sections discusses the possibilities as described in Tab.1. Section 2, describes the BIM based electrical design. Section 3 , discusses the details of BIM based energy analysis. In Section 4, BIM and GIS Integration for power system planning and applications on SBE are discussed. Section 5 discusses the case study followed by a critical evaluation in Section 6 and then the conclusion in Section 7.

Table 1. Potential applications of BIM based electrical modelling

\begin{tabular}{|c|c|}
\hline Category & Applications \\
\hline Electrical & Modeling and design calculations of \\
\hline System & lighting, power and cable routing systems, \\
\hline Design & $\begin{array}{l}\text { panel board design and balancing, lighting } \\
\text { protection,3D visualization and renderings, } \\
\text { quantity take off and cost estimation, } \\
\text { prefabrication detailing, safety analysis, } \\
\text { improved design communication, layout } \\
\text { planning. }\end{array}$ \\
\hline Analysis & $\begin{array}{l}\text { Clash detection, circuit continuity } \\
\text { checking, costing, LEED, daylight analysis } \\
\text { sustainability, RE Potential, whole building } \\
\text { energy analysis. }\end{array}$ \\
\hline $\begin{array}{l}\text { Pow } \\
\text { Plan }\end{array}$ & $\begin{array}{l}\text { Concept of parametric city energy } \\
\text { modeling } \\
\text { and (smart) microgrid/ electrical network } \\
\text { planning }\end{array}$ \\
\hline $\begin{array}{l}\text { Smart bui } \\
\text { environm }\end{array}$ & $\begin{array}{l}\text { Smart objects, behavioral analysis, real } \\
\text { time monitoring and operation and } \\
\text { maintenance, post occupancy evaluation. } \\
\text { real time visualization. }\end{array}$ \\
\hline
\end{tabular}

There are only a few studies on BIM electrical system design and utilization of related semantic information system for electrical grid optimization and city electrical energy modelling [16]-[20]. As most of these studies are carried out by civil or architectural researchers, investigations from an electrical perspective are limited. Earlier studies related to Electrical BIM are mainly based on statistical methods rather than contextualized actual practice. As per McGraw hill construction studies in 2010 and 2014 electrical trade lags behind mechanical trade in BIM adoption by a good margin [8], [21]. Subsequently lag exists in electrical BIM family file development by industries. Most of the electrical contractors making a 3D drawing solely for their own purpose is a rare chance, instead during specialty projects like electricity generating projects $3 \mathrm{D}$ files are developed for better prefabrication and coordination [22]. These observations indicate the importance of a study related to electrical design and maximize its applications in broader areas such that engineers and contractors fully embrace BIM 
and tap its potential. This paper gives further insight for researchers about the future research requirements related to BIM based design electrical applications.

\section{BIM based Electrical System Design and Applications}

Building electrical system are a group of electrical components interconnected to carry out specific operation. By using BIM based ESD, estimation and coordination and manipulations can be carried out before the actual construction starts and adequate solution can be identified and resolved by analysing the BIM virtual model. Construction minutiae are integral to the BIM model making substation and electrical room detailing precisely to scale. Major advantages of BIM are ease repetitive timeconsuming tasks, faster manifold design iteration exploration, arithmetically linked load information, easier coordination and ease of locating appropriate information. In this section, a few typical applications related to BIM based ESD are discussed and starts with lighting system design, power system design and estimation followed. This section conclude by a brief note on API.

From architecture discipline a BIM realistic representation with furniture, wall and ceiling details, window details etc. are available for inserting luminaires, small power outlets and other electrical outlets, leading to more functional and informed design decisions and reduced modelling time and cost savings. So hosting with auto layout options [23] and coordination becomes easier with 3D visualization and parametric interlinking for quantitative and qualitative studies. After inserting the luminaires the same model(in BIM application) can be used for industrially approved lighting calculation, luminance simulations and automatic schedule generation by using in-built tools or external add-on tool to BIM application without a third party software. Similar to DIALux plug-in BIM luminaire IES files with photometric data are getting momentum [24]. Since GIS coordinated integrated model is available, solar and artificial lighting combined energy analysis is possible by using BIM daylight or energy analysis tools [25]. Electrical circuit developed in BIM based applications are based on the concept of functionally interlinked objects that are capable of doing arithmetic calculations.

Similar to lighting an information system backed parametrically linked realistic visualization of electrical circuits for power system can be developed. We can prepare systems for cable tray bus duct, conduits with fittings and draw in scale with an auto-routing option. By virtue of datacentric approach of BIM and logically related concept a panel board schedule is functionally interlinked with its corresponding loads. Panel board auto balance, automatic circuit ampacity calculation, identification of orphaned components are outcomes of this functional relationship in BIM application. In the BIM based electrical circuit modelling embracing a logical system concept, while we try to connect two artefacts that have different voltage leads to error. BIM based project specific customizable template with electrical settings such as voltage, electrical distribution system and wire type when developed, calculation and drafting becomes easier. Colour coding for different subcategories like lighting wiring, power system wiring according to a common rule is a recommended procedure by authorities [6]. By incorporating spatial and temporal data from BIM, Chou, C.-C., et al developed a methodology referred as iARTS (interactive Augmented Reality system for Temporal and Spatial analysis) of power consumption data integrated with building information models) to identify electricity usage pattern and potential adjustments plan for minimizing electricity wastage[26]. BIM based power system computing tools are getting momentum [27] [28], but the most preferred is to incorporate with BIM mainstream power system analysis software packages like ETAP where all kinds of electrical analysis is possible.

Since actual representation of room dimensions and family files used for modelling are directly from manufacturer or modelled as per realistic conditions prefabrication is a very possible entity. Better visualization, accuracy, validation of measurement issue and ease of installation are the major advantages claimed by contractors by using BIM for electrical prefabrication [29]. The use of BIM eased the prefabrication coordination process in MEP trade and has improved the prefabrication on multiple levels [30]. [31] and [32] has undertaken BIM and electrical prefabrication studies and their results suggest a positive impact on productivity. According to the phase of construction or level of building we can prepare a schedule and send it to the manufacturer. By associating Holography techniques with BIM based on Mixed reality concept and with the aid of computer vision capabilities will increase design communication, productivity and ease construction works related to complex critical system like substation [33] [31]. By virtue of 3D visualization and analysis in BIM, safety briefing for workers will be clear and efficient, and logistical arrangement, crane deployment etc. becomes safer [34]. [35] presented a BIM based framework for Facility management safety including electric shock. User controlled automatic clash detection tools are available with BIM application for multidisciplinary coordination. To achieve a smoother coordination, concerned discipline engineers are to be present side by side in one 'Big Room' [36].

By using BIM, while doing estimation and costing the BIM intelligent investigation tools will automatically execute the quantity take off and a schedule is prepared with a flexibility like pivot table of Excel. By combining BIM and costing application with the help of API/Open Database Connectivity (ODBC)/ Industry Foundation Class (IFC) it is possible to conduct complex electrical trade costing, such as the costing related to substation by avoiding large calculation error, providing substantial data and it is much capable than the traditional methods such as MS Excel based calculations[37]. Existing electrical network details can be converted to a BIM model by using 3D scan technology according to our requirements by following the necessary steps [38]. There exists BIM based application tools for calculating lightning protection [39]. The concept of 3D model supported by GIS will ease lightning protection calculation. Virtually we can create a graphical representation for clearance requirements for an electrical equipment as per code such that its clearance requirements can be taken into consideration both visually and programmatically through clash detection. A camera view of electrical room modelled in Autodesk's Revit is presented in Fig. 2. From visually complex 3D BIM model based MEP system it is possible to generate two-dimensional schematic diagrams like the traditional single line diagrams which are more user friendly [40]. Static and dynamic automated site layout planning is facilitated by BIM [41]. MEP layout optimization from its initial design to construction stage is achievable by BIM and there by achieving cost savings [42]. 


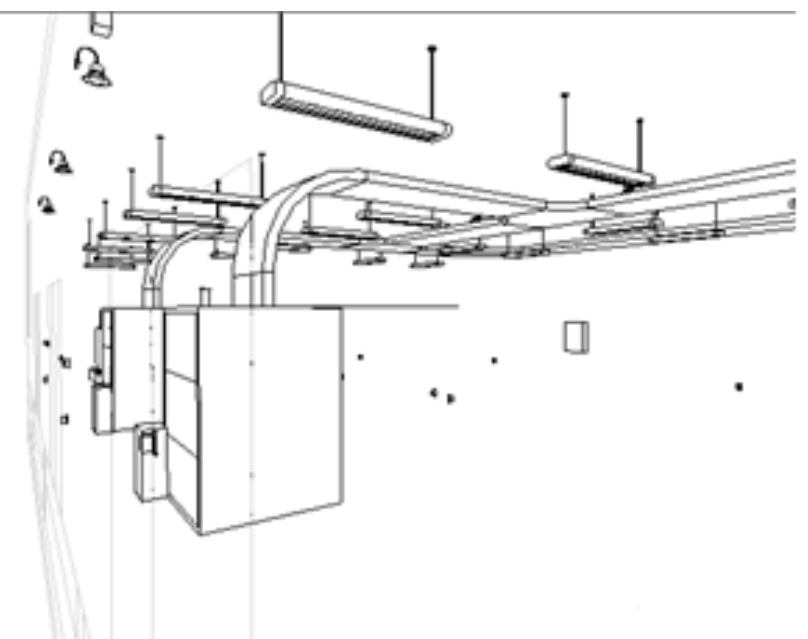

Fig. 2. 3D BIM basic model for an electrical room

Generally, in most of the BIM applications according to the user's requirements a developer's tab and interfacing options are provided. Using Application Programming Interfacing (API) new tools can be added for data manipulation, interoperability and linking to external database. According to the specific needs of the user a new tool is developed which eases his task and thereby increases the productivity. API tools can be developed as either an external Add in type or an internal macro type. API can be developed for creating, editing and retrieving the graphics/parameter/analysis of a particular BIM document like data for grid optimization, costing and energy auditing. Using API we can develop smart objects for design intelligence. Smart objects are the ones which can interact with other artefacts or with user for capturing information or any other intelligent activity [43]. Autodesk Revit provides a powerful API based on .NET by which new tools can be used to conduct automated repetitive tasks. In a BIM authored API plugin has been developed by [44] can capture and record process information like discussions and design coordination decisions related to BIM based design developments such as MEP coordination.

\section{Energy Analysis and Renewable Energy Assessment}

The Emerging renewable energy technologies are becoming more cost effective and are becoming mandatory requirements for new constructions. Finding a combination of renewable energy sources while considering increasing number of conflicting objectives, constraints and uncertainties is a complex and error prone process. Conventional manual Energy Performance Assessments (EPA) methods can cause strenuous issues like repeated and error-prone data replication, data loss, and unnecessary data processing and storage. [45].Also the initial design phase is the advantageous time for energy efficient building planning and integration [46]. Simulation tool used for energy analysis task can deal with renewable energy systems but may lack economic analysis tool, in such a condition integrated application of different software is required [47].To overcome above elucidated matters, a new methodology required with following points for building level energy and RE potential assessment (a) To do a complete building level integrated analysis a real conceptual modelling is required and each and every artefacts including electrical network of that building is to be structured in such a way that changes in any one of the network parameters is to be propagated to other related building components (parametric modelling). (b)Its availability at early phase of project planning can be useful for further optimization study at grid level. (c)To achieve accurate design of integrated energy systems, optimization methods and tools are required that can replicate consolidated nature of these systems [48] (d) Integrated GIS, BIM and Building Energy Management System (BEMS) is required for more intuitive and effective facility and asset management. The above said credentials are unerringly offered by BIM.

Concept of comprehensible integrated BIM modelling enables whole building integrated performance measurements by combining weather data and user preferences. Pre-construction energy analysis in BIM realistic virtual building model helps to analyse environmental contemplations in a relatively seamless way. Instead of traditional energy analysis's simplifying assumptions, BIM method deploy actual quantifiable data on a detailed building model. BIM design models can be used for whole building integrated energy analysis, solar and wind energy potential analysis, HVAC load calculations and daylight simulations. With the help of BIM based Building Performance Simulation (BPS) it is possible to identify the suitable technology matches as per project criteria for energy usage, renewable energy selection, carbon emission and various costs and Leadership in Energy and Environmental Design (LEED) requirements. Complete energy analysis in BIM can be done by conceptual modelling, building components or combined analysis. The energy and RE analysis tools in BIM can be an add-in tool, inbuilt tool or that utilizes the BIM model by exporting in a required manner. For example BIM Model is to be converted to an Input Data Format (IDF) document for building energy simulation in EnergyPlus application. [49]. There exist various BIM based energy analysis software with various capabilities such as Autodesk's Green Building Studio (GBS). The Building Energy Software Tools (BEST) directory lists hundreds of software tools for assessing energy efficiency, renewable energy efficiency and sustainability analysis [50]. Some software can work independently from BIM, while others can be integrated to BIM. Research outcomes from BIM based energy analysis [51] indicate that a well-oriented building can save considerable amount of electricity throughout its life cycle.

By using API it is possible to develop add-in tools that are capable to evaluate Renewable energy potential such as solar. 3D models directly available with accurate details related to the shapes, materials, building components combined with geographical and climatic data can offer a broader analysis tool for Renewable Energy (RE) assessment compared to the existing tools such as PVsyst where designers are required to reconstruct the building model solely for assessment. In an add-in tool method, BIM based Automatic photo-voltaic design tool developed [52] indicate that the method can improve the design efficiency by $265 \%$ as compared to human-based design.

\section{BIM and GIS Integration for Power System Planning}

Increasing energy consumption and greenhouse gas emissions has mounted up to such a level that $40 \%$ of the former and $33 \%$ of the latter are contributed by the building sector [53]. The advancement of suitable urban planning practices is a key point to scale down the energy utilization but contemporary urban planning is not a process that 
ensures energy efficient cities [54]. Accomplishing smart grid and energy retrofitting in buildings would be the significant factors for attaining Zero Carbon homes [55] and optimum energy usage. In the case of smart microgrid planning process attempts to solve the economic feasibility of its deployment and evaluate the optimum generation mix of Distributed Energy Resources (DER) at various operating conditions by satisfying the engineering, financial, behavioral and environmental constraints, which are conflicting to each other. Microgrid is to be outlined in an infrastructure for which electrical system is to be designed and analysed. For maximum gain, it is preferred to perform this planning at the early design stage of an infrastructural development [49]. Independent building level optimization and further optimization at grid level are required for maximizing gain. Above mandates a platform for power system planning at grid /city level that can is able to conduct realistic analysis in faster and easier approach by considering building level conditions.

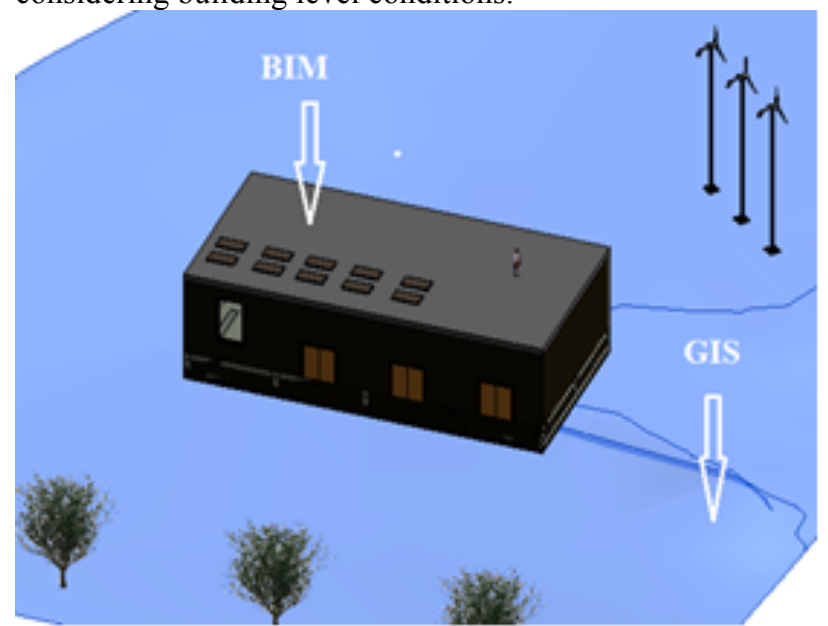

Fig. 3. Geospatial BIM data usage for city level engineering analysis.

A BIM and GIS based electrical power data integration platform is a better solution for life cycle power grid data integration and its related sharing problem as shown in Fig.3, where BIM will provide building level electrical data and optimization studies and GIS integrate the building level data for city level energy studies. Such an approach mandates an integration of planning, design, construction, operation, maintenance and marketing information models related to power system [56]. GIS enable us to visualize, query, investigate, and interpret data to understand associations, characteristics, and trends [57]. Various levels of BIM and GIS integration are possible like semantic web technologies based integration, service-based methods and application level integration, out of which the finest method based on effectiveness, extensibility, effort and flexibility is the method based on semantic web technologies [58]. Optimal integrated planning of a smart microgrid by semantic information system centered bottom up approach based on BIM and GIS will be an effective planning process. BIM based optimization and analysis study is done at building level. Retrofitting the same data for smart microgrid in a project area by utilizing GIS leads to a significant gain in visualization, analysis, forecasting building performance and optimum location selection. Literature study indicates that only limited studies are carried out to evaluate the potential of BIM and GIS integrated approach for increasing energy efficiency of considerable number of buildings [19]. It should be noted that for a collective study of BIM and GIS heterogeneous electrical data from various types of sources, a common platform is to be there according to a common specification [59]. Also it is not a viable task to export a multi-building's BIM files as it is to GIS and to do analysis because normally BIM files will be in megabytes [60]. Therefore special tools are necessary for extraction of necessary electrical parameters from BIM files and export it to GIS platform. Either a data mining technique or a specific application can be used. Static data and dynamic data are required to conduct a smart grid optimization study. BIM model energy analysis provides building level energy requirement data and IFC/API methods possible to extract necessary data from parametric BIM electrical model and export to GIS for a grid level analysis. How BIM can be used for SBE is described in the following paragraph.

BIM has the facility for post and pre-construction applications for SBE design and analysis by the use of BIM model integrated real time monitoring, BIM based smart objects and behavioral analysis. Pre-construction SBE analysis is possible by combining historic data and BIM model. BIM model act as knowledge base for energy efficient SBE development and its usage for lifetime operation and maintenance with the help of an algorithm. Occupant's activity details and perspective and external parameters like climatic conditions can be used to determine effect on various building components including electrical loads to estimate details like daily load curves. Visualization of the measured real time energy usage can be prepared with the help of BIM authored tools or exporting the details to applications like 3D web-browser [61]. Dynamic data about the building, for example, sensor measurements and control signals from the building electrical loads, can be embedded with BIM model with the help of an add-in application or by an interfacing software to help energy optimization, management, operation and maintenance by augmenting actual monitoring data with BIM metadata. BIM-based building management are possible by integrating with software defined networking, measuring devices and building automation systems to achieve better smart grid design exemplary [62]. [63] presented a methodology for BIM real time power monitoring by incorporating real-time power consumption and potential energy saving data with BIM model with the help of an interfacing software. [64] developed a novel smart micro scale energy management system by combining smart sensor methods and BIM, that managing system based on user behavior like interaction between users, indoor comfort, and outdoor atmospheric deviations with the help of multi-objective optimization process. Chen et.al [65] has discussed in 2016 the different methods for developing smart objects. Jack in 2013 has shown by the concept of agent based technique the simulation of human behavior in BIM platform [66]. In an occupant centric framework sensor enabled cubicle was considered and the data from it was collected and was integrated with BIM and visualization and analysis was done [67]. The integration of real time energy usage data, visualization tools and sensor data in a common platform (GIS) can lead to better monitoring and control of energy usage in an intelligent way [68]. Literature review shows that BIM in SBE and its role in energy management, is not well investigated [18].

From these studies, it can be seen that BIM technology can be extended to smart grid modelling and optimization because BIM can be utilized for both static and dynamic realistic simulations. By combining BIM and GIS in 
construction industry both microscopic and macroscopic data are traceable for SBE by the fact that BIM is a standardized method for integrated analysis and 3D visualization of a building and for sharing information in different formats. Fig.4 is a base level computational framework for smart microgrid planning and optimization. All building's ESD inside the proposed project is to be carried out by using BIM application such as Autodesk's Revit or Graphisoft's ArchiCAD. By using BIM energy analysis application such as Green Building Studio (GBS), for each building a complete energy analysis study is to be carried out such that Carbon emission, RE potential and other related data will be estimated. By the help of smart analysis tools as explained above, smart grid related studies are possible with BIM. The necessary static and dynamic data for each building is to be exported to GIS platform by using an API tool purposefully developed for it. A topology of electrical network is to be designed in GIS application by using geometric network tool. This geometric network can be imported into power system analysis application such as ETAP Power Station for various kind of power system analysis studies. Efficient bidirectional data exchange between BIM and GIS as shown in Fig.4 leads to more accurate realistic power system analysis in a shorter time. It is to be noted these applications are developed for different purposes, so a bidirectional information sharing between applications become a major concern for data integration.

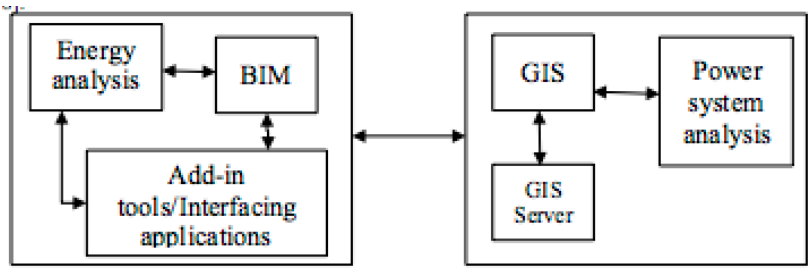

Fig. 4. A proposal for base level computational framework for smart microgrid planning and optimization

\section{Case Study}

A case study for an indoor substation MEP design is done in Autodesk Revit platform as shown in Fig.5 (a). A sample lighting design for an office room having a dimension of $3.7 \times 4 \times 3$ meters inside the substation is done as follows. As per lighting codes the illuminance level requirements for offices are 500 Lux. Work plane for this office room is 0.8 meters from finished floor level. The room is modelled in Autodesk Revit with furniture, doors, windows and the wall type selected is basic wall type. Luminaire selected is a surface mounted fluorescent lighting fixture and hosted at the ceiling. Lighting analysis is done with Elum [69] add-in tool for Autodesk Revit. Fig. 5(b) shows a room lighting design results, pseudo colouring shows lighting intensity as per the range shown below the drawing. The values to summarize a lighting design such as maximum, minimum and mean values for illuminance and its uniformity are obtainable easily. In the same platform of Revit it is possible to conduct concerned authority approved lighting analysis for multiple rooms and present the results in a flexible schedule according to the user requirements. New versions of Revit add-in lighting analysis tools are upgraded with sophisticated computational tools. Power system equipment's and cable routing are modelled and Panel design done. Interface check tool in Revit is utilized for the coordination of MEP systems above false ceiling, for detecting clashes between artefacts and also for finding design errors. The clashes between corresponding category elements are obtained and necessary corrections are done. Fig.5(c) shows an instance of overlapping in which a lighting fixture clashes with a Heating, Ventilation and Air Conditioning (HVAC) duct. This is automatically detected by the software while we run an interface check tool and interfacing report obtained clearly shows the ID of overlapping elements and by clicking 'show' button it is possible to precisely locate the related elements.

Table 2. Energy analysis outcomes by GBS for the developed case study

\begin{tabular}{l|l}
\hline Description & Outcomes \\
\hline Project Name & Elec Substation \\
Floor Area & $197 \mathrm{~m}^{2}$ \\
Exterior Wall Area & $280 \mathrm{~m}^{2}$ \\
Electricity Use Intensity & $176 \mathrm{kWh} / \mathrm{sm} / \mathrm{yr}$ \\
Life Cycle Electricity Use: & $823,834 \mathrm{kWh}$ \\
Roof Mounted PV System (Medium & $38,926 \mathrm{kWh} / \mathrm{yr}$ \\
efficiency):Potential & \\
Annual Carbon Emissions due to & 9 metric tons/year \\
Electricity consumption & \\
\hline
\end{tabular}

A whole building energy analysis is conducted for developed substation building for analysing energy requirements as per project specifications by using GBS, after energy setting and massing are done using appropriate tools and options in Revit. Then, using GBS energy analysis various results such as building performance factors, energy use intensity, renewable energy potential, carbon footprint implications, potential energy saving options and detailed monthly reports are obtained. Energy analysis outcomes for the case study are given in Tab. 2. In GBS immediate alternatives are available as per constraints for comparison studies instantaneously and it is possible to enter weather data manually at Revit's energy setting options. Also, iterations with different building orientations can be done with GBS. Fig. 5(d) shows annual electric end use details for the case study. It to be noted that solar energy potential are estimated for low, medium and high efficiency panels by assuming both horizontal and tilted surfaces of the building by GBS. Wind energy potential is based on electricity generated by a horizontal wind generator of 7.5 foot radius in which the annual wind data is obtained from the nearest weather station.

An API tool is developed as an Autodesk Revit external add-in for retrieving project info, total number of lighting fixtures and its total $\mathrm{kW}, \mathrm{kVA}$ and power factor for an electrical BIM model. A windows form is developed as shown in Fig.6 using the Visual Studio Development Environment for C\# with proper reference to Autodesk user interface. The source code of windows form start with Revit DB links. The BIM model opened in Revit is assigned as active user interface document. By using 'element category filter' function lighting fixtures are filtered and collected in a list. By counting the elements in the list the total count value is assigned to the textbox's text attribute for displaying the counting result. 'get parameter function' in a 'for each' loop is used for each and every electrical connectors of the lighting fixtures in the list to gather the built-in parameter values of corresponding wattage and power factor. By summing the values of concerned wattage values of lighting fixtures the total sum is assigned to a textbox's text attribute for displaying the total wattage of lighting fixtures in the building BIM model. By assuming all loads having lagging 
or unity power factor and dividing each and every lighting fixture wattage with corresponding power factor and summing the outcome, the total Volt-ampere for lighting fixtures is calculated. The ratio of total wattage to total Voltampere is assigned to the textbox's text attribute for displaying the total power factor of all lighting fixtures. To

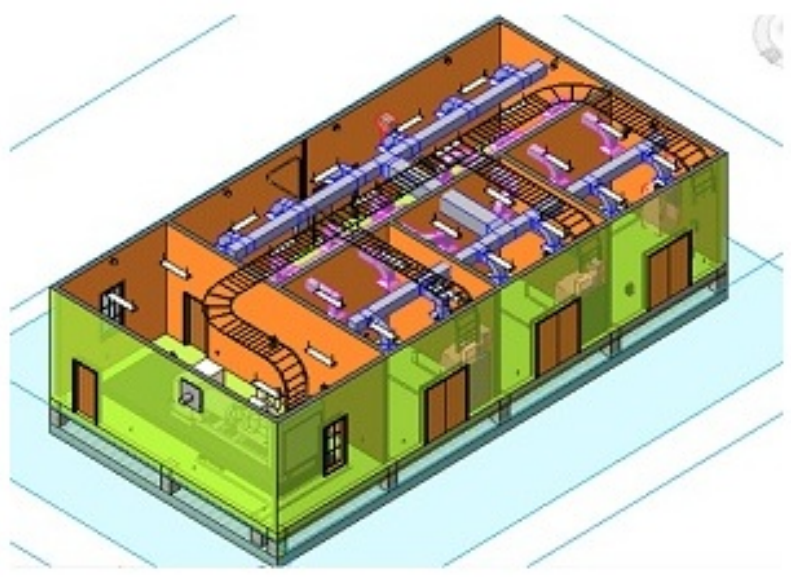

(a)

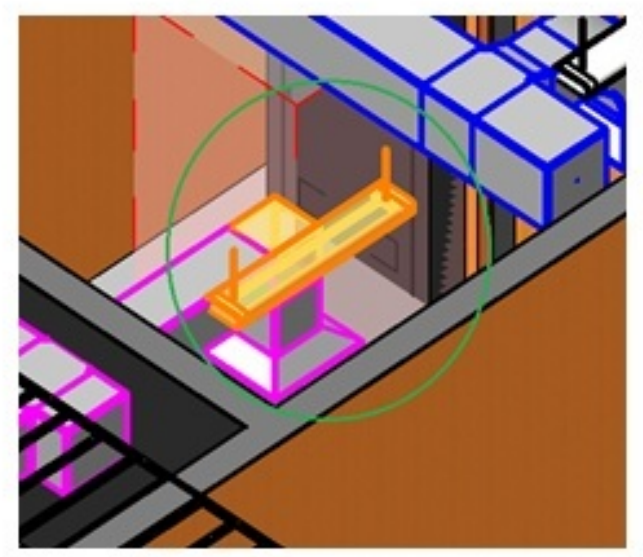

(c) generalize the tools as discussed above for different projects a common project specification is required for designers and also a more sophisticated programming. Otherwise, it may lead to errors when we deploy the same tool in another platform.

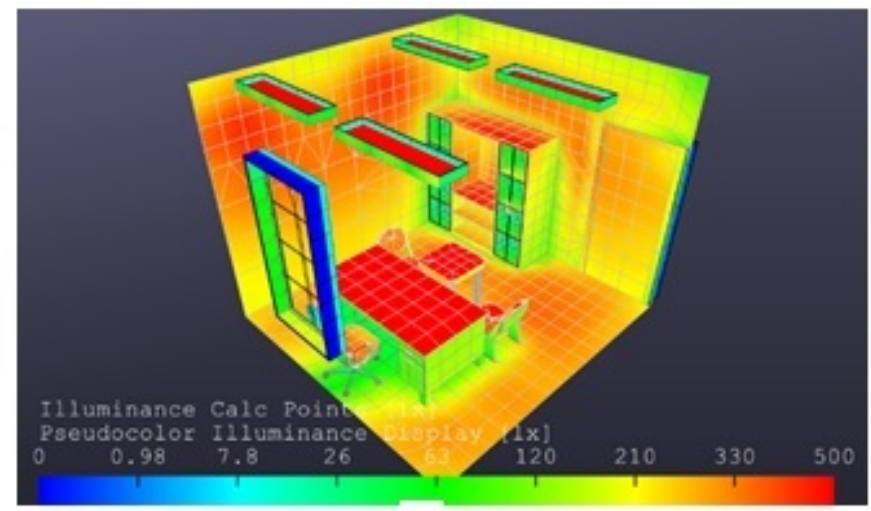

(b)

Annual Electric End Use
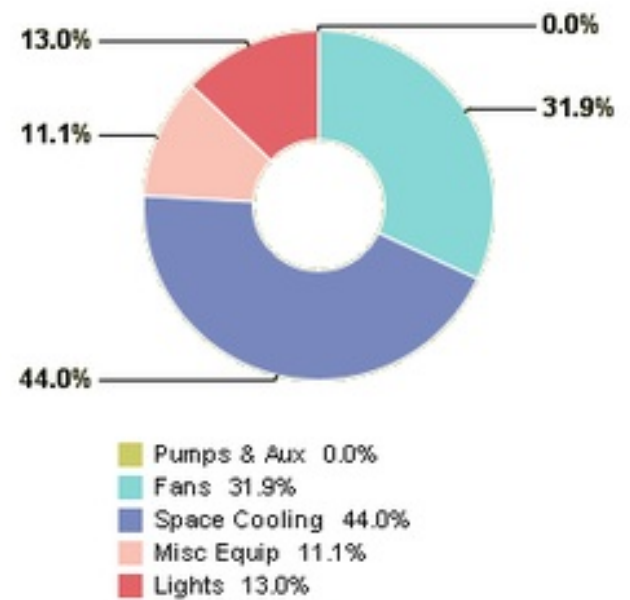

(d)

Fig.5 (a). A clipped view of modelled substation. Fig.5 (b). Pseudocolor display of calculated illuminance using Elum tools for an office room. Fig.5(C). An instance of overlapping detection using Revit clash detection tool. Fig. 5(d). Annual electric end use details for the case study by Green Building Studio whole building energy analysis.

\begin{tabular}{|c|c|c|c|}
\hline \multicolumn{2}{|l|}{ 啰 Light-Info } & & $x$ \\
\hline Project Name & Project-1 & No of Luminaires & 34 \\
\hline Lighting Load (KW) & 1598 & Lighting Load (KVA) & 1815.90 \\
\hline Power Factor & $0.88 \mathrm{lag}$ & $\begin{array}{r}\text { Calculate } \\
\end{array}$ & Export to GIS Database \\
\hline
\end{tabular}

Fig. 6. An add -in tool for extracting Lighting information from a BIM model

In Autodesk Revit, as like Fig. 6 and its related programming a case study can be developed for assigning a real time gathered data to a BIM element parameter value by using API. The corresponding element is filtered and by using 'get and set parameter function' the corresponding value is changed to the collected real time data

\section{Critical Evaluation}

In this paper, the capabilities and possibilities of BIM based electrical design and its applications have been discussed.
BIM is changing the way in which designers, software specialist and contractors work. It can be seen that the initial phases of design, coordination and analysis in a BIM environment consumes significant amount of time compared to $2 \mathrm{D}$ CAD set up. However, this extra time requirement gets completely nullified in the later phases of prefabrication, installation and rework related design changes of the project. The same file can be used for analysis, GIS or SBE and data rich BIM families are user friendly compared to $2 \mathrm{D}$ drawings. Integrated $3 \mathrm{D}$ virtual realistic modelling and analysis technique can trace out uncertainties about various design elements at the early stage of project implementation. Phasing of projects and ndimensional construction planning such as 4D-Schedule, 5D-Cost, 6D-life cycle analysis, 7D-Building occupancy model are the inherent features of BIM. Benefits are visualization, coordination, flexibility to changes, ease of data sharing, a reality model for analysis, waste and rework reduction, detection of orphan elements in circuit, post and pre-construction usage, automatic conflict detection and automatic or semi-automatic calculations, cost estimation 
and value engineering, phasing of projects, lifecycle deployment, a single platform for various detailed analysis, and ease of sections. Typical projects in various locations can be easily modelled with BIM using the semantic database and thereby significantly reducing the computational requirements.

However, while applying BIM, many challenges such as hardware cost, software cost, training cost, reluctance to embrace, customized families and tools development are to be overcome. Compared to 2D-CAD modelling, substantial skill, talent and discipline are compulsory to develop and operate in a BIM environment. The greatest obstacle for the utilization of BIM in construction project is the adoption process by stakeholders regardless of the software capabilities [30]. Maturity and granularity of existing BIM tools and families are to be extrapolated for realistic engineering analysis. The applications used in BIM MEP design are still to be matured [70]. It is observed that the BIM tools are getting evolved during this period. However, it is necessary to have an integrated user friendly platform with the facilities such as automatic generation of single line diagram, feeder schedule with voltage drop, cable sizing and circuit breaker sizing as per the approved codes. Such an integrated platform can enable one to take full advantage of the model data for system analysis. According to the study conducted by Thomas Reeves on validation of energy models by different BIM applications, software incapacity is a likely source of error for the realistic analysis of lighting simulations [71]. In the case of a substation equipment LoD is preferably high, but in case of a single receptacle in a general purpose building LoD required is less. Compared to civil or mechanical LoD requirements for electrical trade is less which results in a lag in BIM deployment. It will be costlier and unnecessary to model every simple conduit connection between a lighting or power outlet and panel board in 3D. The manufacturer's product BIM model are not generally well characterized due to uncertainties related to the scope and the substance of the model parameters [72]. Often data exchange between the architect and the simulation specialist is an error-prone process [73]. Industry Foundation Classes (IFC) is a standard file format for data exchanges between BIM related applications. It was not intended to hold all necessary data such as real time sensor data for various studies [74]. Unrealistic simplification of BIM information to make them compatible with energy simulation applications, may cause the removal of related construction information in BIM objects. Further Interoperability issues between BIM model and energy simulation applications also form barriers for the reliable
EPA [45]. Compared to BIM usage in design and construction phase, its use in facility lifecycle phase is in its infancy [35].

\section{Conclusion}

This paper has discussed BIM based electrical system design and its applications along with related literatures and case studies. Fast growing BIM technology's proliferation is envisioned to be developed in a controlled manner for electrical trade, life cycle deployment for commercial success and geographical level application and smart grid usage. For maximizing this technology and its wide spread usage in electrical trade, further research is required for the utilization of BIM for smart built environment, grid optimization, advancement in BIM electrical smart objects and BIM integration with power system analysis software. To further boost BIM for electrical trade, long-term planning and favorable construction strategies, common standards and freeware BIM applications are to be brought up. The potential of emerging BIM have been seldom considered for electrical design studies. Significant efforts are required from both government agencies and researchers to standardize BIM methods related to electrical/power engineering. The manufacturer based BIM object model is to be compatible with electrical design studies and various analyses. Instead of the customized development, a standard methodology is required for BIM electrical family parameters to avoid dissimilarities. BIM applications are to be further advanced to cater to the industrial and sustainable requirements with more user friendly tools with the capabilities to conduct detailed engineering studies on one platform, the BIM, for all kinds of electrical engineering modelling, design and analysis. Further research is required for the development of BIM authored tools for power demand estimation or renewable energy estimation according to various codes. A preconstruction optimization based on different building orientation in a multi-building microgrid and its impact on energy saving is to be carried out with the help of BIM based energy applications and computational techniques. A good topic of research is to conduct a pre-construction industrial level smart grid optimization analysis with the help of BIM by combining historical data, energy analysis and behavioral studies.

This is an Open Access article distributed under the terms of the Creative Commons Attribution Licence

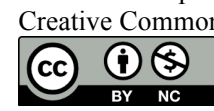

\section{References}

[1] "Building Information Modelling," HM government, gov.uk, Rep. URN $12 / 1327$.

[2] C. Eastman et al., "An Outline of the Building Description System," Institute of Physical Planning, Carnegie-Mellon University, Pittsburgh, PA, Rep.RR-50, Sep., 1974.

[3] L. H. Forbes and S. M. Ahmed, "Modern Construction: Lean Project Delivery and Integrated Practices," FL, CRC Press, 2011.

[4] C. Eastman et al., BIM Handbook: A Guide to Building Information Modeling for Owners, Managers, Designers, Engineers and Contractors, 2nd ed. New Jersey: John Wiley \& Sons, 2011

[5] "Government Construction Strategy 2016-20 March 2016," The Infrastructure and Projects Authority, gov.uk, 2016.

[6] "BIM Essential Guide for MEP Consultants," Building and Construction Authority, Singapore, 2013.
[7] Schneider. (retrieved on 12th Sep. 2017). Building Information Modelling [Online]. Available: http://www.schneiderelectric.co.uk/en/work/support/bim/

[8] S. Jones, "Recent Smart Market BIM Research by McGraw Hill Construction," presented at the Building Innovation 2014., Washington D.C., WA, 2014.

[9] R. Luming and V. Singh, "Comparing BIM in Construction with 3D Modeling in Shipbuilding Industries: Is the Grass Greener on the Other Side?," in Product Lifecycle Management in the Era of Internet of Things, 2015, Springer, vol 467 IFIP Advances in Information and Communication Technology 2016, pp. 193-202.

[10]Bentley. (retrieved on 12th Sep. 2017). Parametric Design Application of Hydropower Engineering [Online]. Available:https://www.bentley.com/en/project-profiles/beifang- 
investigation-design-and-research parametric-design-applicationof-hydropower-engineering.

[11] Autodesk. (retrieved on 12th Sep. 2017). Revit, Built for BIM, [Online]. Available: http://www.autodesk.com/products/revitfamily/overview.

[12] Graphisoft (retrieved on 12th Sep. 2017). What is ARCHICAD? [Online]. Available: http://www.graphisoft.com/archicad/

[13]Bentley (retrieved on 12th Sep. 2017). Substation Design Solution [Online].

Available: https://www.bentley.com/en/solutions/substation-design

[14]Primtech (retrieved on 12th Sep. 2017). Engineering Solution for Optimized Substation Design of High Voltage Substations [Online]. Available: http://www.primtech.com/pages/usuk/

[15]Dial. (retrieved on 12th Sep. 2017). Lighting design software DIALux Professional lighting design with DIALux. [Online]. Available: https://www.dial.de/en/dialux/

[16]J. Zhou et al, "Discussion of "State of Practice of Building Information Modeling in the Electrical Construction Industry" by Awad S. Hanna, Michael Yeutter, and Diane G. Aoun,” Journal of Construction Engineering and Management, Mar 2016, vol 142, issue 3 .

[17] Salman Azhar and Seth Cochran, "Current Status of Building Information Modeling (BIM) Adoptability in the U.S. Electrical Construction Industry," in Fifth International Conference on Construction in the 21 st Century, Istanbul, Turkey, 2009, pp.13871394.

[18]J Zhang et al, "Building Information Modelling for Smart Built Environments," in Proc. Building A Better New Zealand, 2015 C MDPI. doi:10.3390/buildings5010100.

[19] Wei : Wei Wu, Xiaoming Yang and Qin Fan , “GIS-BIM Based Virtual Facility

Energy Assessment (VFEA) - Framework Development and Use Case of California State University," in Computing in Civil and Building Engineering, 2014 (C) ASCE. doi:10.1061/9780784413616.043.

[20] Awad S. Hanna, Michael Yeutter, Diane G. Aoun, "State of Practice of Building Information Modeling in the Electrical Construction Industry," Journal of Construction Engineering and Management, Volume 140, Issue 12, Dec, 2014.

[21]"Green BIM How Building Information Modeling is Contributing to Green Design and Construction," McGraw Hill Construction., Bedford, MA, Rep.1-800-591-4462, 2010.

[22]L. Simonian, "Building Information Modeling for Electrica Contractors :Current Practice And Recommendations," San Luis Obispo, CA, 2009.

[23]H. Kim et al, "Auto-layout of Lighting Objects to Support Lighting Design in the Early Phase of Design," 33rd Int. Symp. on Automation and Robotics in Construction., Auburn, AL, 2016, pp.761-769.

[24]Philips. Lighting (retrieved on 12th Mar. 2017). BIM-Revit Library [Online].

Available:http://www.lighting.philips.com/main/support/support/r evit-library.html\#page $=1$

[25]S. Azhar and J. Brown, "BIM for Sustainability Analyses", International Journal of Construction Education and Research, vol. 5, no. 4, pp. 276-292, 2009.

[26]C. Chou, C. Chiang, P. Wu, C. Chu and C. Lin, "Spatiotemporal analysis and visualization of power consumption data integrated with building information models for energy savings", Resources, Conservation and Recycling, vol. 123, pp. 219-229, 2017.

[27]Design Master. (retrieved on 12th Sep. 2017). Design Master Electrical RT. [Online]. Available: http://www.designmaster.biz/revit/

[28] POWERCAD. (retrieved on 12th Sep. 2017). Streamlining Your Electrical Design Workflow. [Online]. Available: http://www.powercad-r.com/

[29]L. Simonian and T. Korman, "Prefabrication within the Electrical Construction Industry - a Survey of Electrical Contractors." in Proc. of the 19th CIB World Building Congress, Brisbane 2013: Construction and Society, Brisbane, Queensland, 2013.

[30]T. Korman and N. Lu, "Innovation and Improvements of Mechanical, Electrical, and Plumbing Systems for Modular Construction Using Building Information Modeling", AEI 2011, 2011.

[31] Chalhoub and S. Ayer, "Mixed Reality for Electrical Prefabrication Tasks", Computing in Civil Engineering 2017, 2017.

[32]H. Khaleghian, Y. Shan and P. Lewis, "A Case Study of Productivity Improvement by Electrical Prefabrication", Construction Research Congress 2016, 2016.
[33]A. Cardoso, I. do Santos Peres, E. Lamounier, G. Lima, M. Miranda and I. Moraes, "Associating Holography Techniques with BIM Practices for Electrical Substation Design", Advances in Intelligent Systems and Computing, pp. 37-47, 2017.

[34] C. L. Mak.(retrieved on 12th Sep. 2017). Beauty of BIM Powers Safety First Approach [Online]. Available:,http://www.autodesk.com/temp/pdf/CLP_Power_Hong Kong_Limited1.pdf

[35]E. Wetzel and W. Thabet, "The use of a BIM-based framework to support safe facility management processes", Automation in Construction, vol. 60, pp. 12-24, 2015

[36]A. Khanzode et al., "Benefits and Lessons Learned of Implementing Building Virtual Design and Construction (VDC) Technologies for coordination of Mechanical, Electrical, and Plumbing (MEP) Systems on a Large Healthcare Project," ITcon, vol. 13, pp. 324-342, Jun.2008.

[37] R. Liu, Y. Xu and X. Zeng, "BIM Application Implementation Plan and Roadmap in the Cost Management of Electric Power Engineering", ICCREM 2014, 2014.

[38]B. Godager, "Analysis of the information needs for existing buildings for integration in modern BIM-based building information management," in 8th Int. Conf., Vilnius, Lithuania, 2011, pp. 886-892.

[39] M. Kokorus et al., "Innovative Approach to the Substation Design using Building Information Modeling (BIM) Technology," in Transmission and Distribution Conference and Exposition (T\&D), 2016, (C) IEEE. doi: 10.1109/TDC.2016.7519983.

[40] M. Matsubayashi and S. Watanabe, "Generating two-dimensional schematic diagrams of mechanical, electrical, and plumbing systems from three-dimensional building information models", International Journal of Architectural Computing, vol. 14, no. 3, pp. 219-232, 2016.

[41]S. Kumar and J. Cheng, "A BIM-based automated site layout planning framework for congested construction sites", Automation in Construction, vol. 59, pp. 24-37, 2015.

[42]J. Wang, X. Wang, W. Shou, H. Chong and J. Guo, "Building information modeling-based integration of MEP layout designs and constructability", Automation in Construction, vol. 61, pp. 134-146, 2016.

[43] S.Y. Chen et al, "Smart BIM object for design intelligence" in Proc. of the 21st International Conference of the Association for Computer-Aided Architectural Design Research in Asia, Hong Kong, 2016, pp. 457-466.

[44]L. Wang and F. Leite, "Process Knowledge Capture in BIM-Based Mechanical, Electrical, and Plumbing Design Coordination Meetings", Journal of Computing in Civil Engineering, vol. 30, no. 2, p. 04015017, 2016.

[45] J. Choi, J. Shin, M. Kim and I. Kim, "Development of openBIMbased energy analysis software to improve the interoperability of energy performance assessment", Automation in Construction, vol. 72 , pp. 52-64, 2016.

[46]R. Sebastian et al., "Semantic BIM And GIS Modelling For Energy-Efficient Buildings Integrated in a Healthcare District," in ISPRS 8th 3DGeoInfo Conference, Istanbul, Turkey, 2013, pp. $255-260$

[47]BIM-PSU, (retrieved on 12th Sep. 2017). "BIM execution planning, facility energy analysis," [Online]. Available: http://bim.psu.edu/Uses/Energy_Analysis.aspx

[48]G. Mendes et al, "Multi-Building Microgrids for a distributed energy future in Portugal," in Int. Conf. on Applied Energy ICAE., Suzhou., China, 2012, pp.1-10.

[49]D. Jung, D. Lee and S. Park, "Energy operation management for Smart city using 3D building energy information modeling", International Journal of Precision Engineering and Manufacturing, vol. 15, no. 8, pp. 1717-1724, 2014.

[50]"Best Directory | Building Energy Software Tools", Buildingenergysoftwaretools.com, 2017. [Online]. Available: https://www.buildingenergysoftwaretools.com/home. [Accessed: 04- Sep- 2017.

[51]F. Abanda and L. Byers, "An investigation of the impact of building orientation on energy consumption in a domestic building using emerging BIM (Building Information Modelling)", Energy, vol. 97, pp. 517-527, 2016.

[52] G. Ning, L. Junnan, D. Yansong, Q. Zhifeng, J. Qingshan, G. Weihua and D. Geert, "BIM-based PV system optimization and deployment", Energy and Buildings, vol. 150, pp. 13-22, 2017.

[53]"Buildings and climate change Summary for decision makers", UNEP DTIE, Paris, ISBN: 987-92-807-3064-7, 2009. 
[54] M. Amado, F. Poggi and A. Amado, "Energy efficient city: A model for urban planning", Sustainable Cities and Society, vol. 26, pp. 476-485, 2016.

[55]Z. Ozturk and Y. Arayici, "Transition process for smart grid compatibility in residential buildings," in International Postgraduate Research Conference., University of Salford, U K, 2011.

[56] G. Yang, H. Zheng, H. Ouyang, J. Zhao, T. Li and J. Zhou, "A Data Integration Platform Research of Power Grid Whole Life Management Based on BIM", Applied Mechanics and Materials, vol. 347-350, pp. 1935-1939, 2013.

[57]ESRI. (retrieved on 12th Sep. 2017). What is GIS? [Online]. Available: http://www.esri.com/what-is-gis

[58]X. Liu, X. Wang, G. Wright, J. Cheng, X. Li and R. Liu, "A Stateof-the-Art Review on the Integration of Building Information Modeling (BIM) and Geographic Information System (GIS)", ISPRS International Journal of Geo-Information, vol. 6, no. 2, p. 53, 2017.

[59]E. Timinskas and M. Davicijonaite, "How to prepare engineering data and graphic systems for smart country," in The 13th International Conference on Engineering and Computer Graphics, 2015, doi: 10.3846/baltgraf.2015.012.

[60] A. Alsaggaf and A. Jrade , "Benefits of integrating BIM and GIS in construction management and control", in The CSCE International Construction Specialty Conference 2015, 2015, doi: $10.14288 / 1.0076369$.

[61]D. Lee, G. Cha and S. Park, "A study on data visualization of embedded sensors for building energy monitoring using BIM", International Journal of Precision Engineering and Manufacturing, vol. 17, no. 6, pp. 807-814, 2016.

[62] Gaolei Li, Jun Wu, Longhua Guo, Jianhua Li, Hongkai Wang, "SDN based dynamic and autonomous bandwidth allocation as ACSI services of IEC61850 communications in smart grid", Smart Energy Grid Engineering (SEGE) 2016 IEEE, pp. 342-346, 2016.

[63]M. Alahmad, W. Nader, J. Neal, J. Shi, C. Berryman, Y. Cho, S. Lau, H. Li, A. Schwer, Z. Shen, J. Stansbury and T. Zhang, "Real Time Power Monitoring \&amp; integration with BIM", IECON
2010 - 36th Annual Conference on IEEE Industrial Electronics Society, 2010.

[64] S. Habibi, "Micro-climatization and real-time digitalization effects on energy efficiency based on user behavior", Building and Environment, vol. 114, pp. 410-428, 2017.

[65]J. Chen et.al, "A Case Study of Embedding Real-time Infrastructure Sensor Data to BIM", ASCE, Construction Research Congress 2014, doi: 10.1061/9780784413517.028.

[66] J. C. P. Cheng and V. J. L. Gan "Integrating Agent-Based Human Behavior Simulation with Building Information Modeling for Building Design," Int. Journal of Engineering and Technology, vol. 5, no. 4, Aug 2013.

[67]R. Attar et al., "Sensor-enabled Cubicles for Occupant-centric Capture of Building Performance Data" Proceedings of the ASHRAE Annual Conference, Montreal, Canada, pp.1-8.

[68]S. Torabi et al. "BIM-GIS modelling for sustainable urban development," in TOWARDS POST-CARBON CITIES SMART BUILT ENVIRONMENT16, Turin, Italy, Mar. 2016.

[69]ElumTools. (retrieved on 12th Sep. 2017). What is ElumTools? [Online]. Available: http://www.elumtools.com/

[70]M. Pejanovic et al., "MEP Design and BIM," in Planning, Design, Construction and Building Renewal INDIS 2012, Novi Sad, RS, 2012.

[71]T. Reeves et al., "Validation of Building Energy Modeling Tools: Ecotect, Green Building Studio and Ies", Proceedings of the 2012 Winter Simulation Conference, Gainesville, FL, 2012.

[72] A. Hanna, F. Boodai and M. El Asmar, "State of Practice of Building Information Modeling in Mechanical and Electrical Construction Industries", Journal of Construction Engineering and Management, vol. 139, no. 10, p. 04013009, 2013.

[73]P. Nageler, G. Zahrer, R. Heimrath, T. Mach, F. Mauthner, I. Leusbrock, H. Schranzhofer and C. Hochenauer, "Novel validated method for GIS based automated dynamic urban building energy simulations", Energy, vol. 139, pp. 142-154, 2017.

[74] A. Redmond, A. Hore, M. Alshawi and R. West, "Exploring how information exchanges can be enhanced through Cloud BIM", Automation in Construction, vol. 24, pp. 175-183, 2012. 